\title{
GACKI ČAKAVSKI GOVORI S PODRUČJA OTOČCA - ZAŠTIĆENO NEMATERIJALNO KULTURNO DOBRO REPUBLIKE HRVATSKE
}

\author{
Milan Kranjčević \\ Katedra Čakavskog sabora pokrajine Gacke \\ Ul. kralja Zvonimira 16 \\ HR 53220 Otočac \\ mkranjcevic@hgk.hr
}

\author{
UDK: 81'28(497.5Otočac) \\ 811.163.42’282(497.5Otočac) \\ Pregledni članak \\ 9.08.2019.
}

Gacki čakavski govori na području Gacke starinački su govori te pripadaju čakavskomu narječju. Klasifikacijom spadaju u ikavsko-ekavski dijalekt, a potom se dijele na dvije grupe poddijalekata - rubni i kontinentalni (Kuterevo), a zatim na mjesne govore pojedinih naselja.

Gacka čakavština je, povijesno gledano, ostatak nekadašnje prevladavajuće čakavštine na prostoru današnje Gacke, Like i Krbave, ali i mnogo šire. Zbog osmanlijskih prodora u srednjemu vijeku to jezično područje je na crti Vrbas - Neretva potiskivano prema zapadu te je došlo do naseljavanja novoga žiteljstva koje je pripadalo štokavskomu narječju. U suvremenosti je gacka čakavština očuvana u dva areala: na području Otočca $i$ na području Brinja. Ona se oslanja na senjsku, odnosno modruško-ogulinsku čakavštinu i dalje, sve do južnih krajeva Karlovca, odnosno Ozlja.

Gacka čakavština je, kao i svi neštokavski govori, ali i mnogo štokavskih, bila potiskivana u prostoru javne komunikacije. Trebalo je podosta napora da se izvorni govornici osmjele i ohrabre njome čim više koristiti. Katedra Čakavskog sabora pokrajine Gacke je i osnovana s ciljem promidžbe i zaštite ove čakavštine. Sve je to nakon dvadesetogodišnjeg djelovanja Katedre rezultiralo 2018. zaštitom Gacke čakavštine s područja Otočca kao nematerijalne kulturne baštine Republike Hrvatske.

Ključne riječi: gacka čakavština, nematerijalna kulturna baština, Otočac

\section{Uvod}

Gacki čakavski govori prostiru se u otočkomu i brinjskomu arealu. Otočki su u uporabi u Otočcu, Ramljanima, Sincu, Lešću, Čoviću, Prozoru, Lipovlju, Kuterevu, Švici, Kompolju i Dabru, dok su brinjski u uporabi u Brinju, Letincu, Lipicama, Stajnici, Križpolju, Jezeranama, Križ Kamenici, Brinjskoj Kamenici i Glibodolu. ${ }^{1}$

\footnotetext{
${ }^{1}$ M. KRANJČEVIĆ, 2009, 401-402.
} 
Gacki čakavski govori su starinački govori. Na području Otočca njima govori oko 9.000 govornika, dok na području Brinja govori njih oko 3.700 . Međutim, općim trendovima depopulacije stanovništva, opada i broj autohtonih govornika i po toj osnovi gacki čakavski mjesni govori iziskuju povećanu brigu oko očuvanja govora i potrebu za njihovom zaštitom.

\section{Osnovne dijalektološke karakteristike gackih čakavskih govora}

Osnovne dijalektološke karakteristike gackih čakavskih govora temelje se na autorovim vlastitim terenskim istraživanjima. Svi gacki čakavski govori pripadaju ikavsko-ekavskom dijalektu te se poddijalekatskom kategorizacijom svrstavaju u rubni poddijalekt, osim Kutereva koji pripada kontinentalnomu poddijalektu ${ }^{2}$. Po stupnju čakavnosti ${ }^{3}$ pripadaju prvom ili najvišem stupnju, osim kuterevskoga koji pripada srednjem stupnju.

U svim govorima jat se dosljedno reflektira po Jakubinskij-Meyerovom pravilu, pa oni spadaju u ikavsko-ekavski dijalekt (bîlit, dîte, mïsec, mïrit, tïme, trîzan, bljêd, cvêt, cêl, vërovat, lësa).

Samoglasnički inventar ovih govora sastoji se od pet samoglasnika. Brinjski govori poznaju diftong /uo/ i /ie/ (brestuôv, lavuôr; ćiêr, liêska), a lešćarski, čovićki i sinački diftong /ie/ (Liẽšće, vodie, pečiê). Od suglasničkoga inventara donedavno nije bila razvijena afrikata /d/ i /dž/ utjecajem školstva i medija (mëja, prëja, žẽja, släje, grozjê, jübar, ali đâk, đübar, lẽđa; žëp, žïgerica, kanžỉja, žëlep). Primarno ne poznaju ni konsonant $/ h /$ koji mijenjaju u $/ j /$ (snäja, strïja, lĩja - lijeha), u /v/ (krûv, trbûv, püv, düv) ili ga izostavljaju (R̈vacka, öću, vätat, narânit, lâd). Pod utjecajem školstva i medija u novije vrijeme ipak se ovaj konsonant probija (automehäničar, Hr̈vat, tëhnjičar).

Zamjenicu čă poznaje većina gackih čakavskih govora, osim dabarskoga i kuterevskoga, ali i kod njih je poznat genitivni oblik čësa. Također govori koji poznaju zamjenicu ča poznaju i priloge zâč , nấč, pốč, pödač i $\hat{u} \breve{c}$.

Poluglas u slabomu položaju je vokaliziran (väjk, kadì, mäša, mälin, mänon, zämen).

Refleks nazalnog vokala /ę/ u /a/ sačuvan je tek u tragovima (jäčmen, njãdra, gnjâzdo), dok prevladava refleks /ę/u /e/ (jezîk, jëdro).

Akcenatski sustav čakavskih govora s područja Otočca odlikuje konzervativizam. On je troakcenatski (kratkosilazni, dugosilazni akcent i akut),

${ }^{2}$ I. LUKEŽIĆ, 1990, 105.

${ }^{3}$ B. FINKA - M. MOGUŠ, 1981. 
dok kuterevski mjesni govor i svi brinjski govori imaju također troakcenatski sustav s tim da je u njima drugačija distribucija naglasaka. U brinjskim se govorima sporadično pojavljuju dugouzlazni (rúka, národ) i kratkouzlazni akcent (kònak, mèdvid). Po tipu akcentuacije $\mathrm{e}^{4}$ ovi govori pripadaju novijem tipu jer je došlo do promjene naglaska na staromu mjestu (rukẽ, rukê; sũša, sûša), odnosno do promjene mjesta s uporabom staroga naglasnog inventara (rukê, rûke). Gacki su govori izgubili dužine, osim u brinjskim govorima gdje se zadržava prednaglasna dužina (vīkälo, brez rūkiê).

Kod svih ovih mjesnih govora svojstvena je zamjena frikativa afrikatom u zatvorenom slogu (nïš, Otöšca).

Prijelaz dočetnoga $-m \mathrm{u}-n$ svojstven je svima govorima (vïdin, čüjen, njôn, vrĩdnin, moîn),a u nekim slučajevima je moguć i u medijalnomu položaju (krunpîr, slãnjka, zapãntit, Kõnpolje). U brinjskim govorima se dočetni - $m$ može i zadržati (ïmam, kvantûm, štîlnicom).

Dočetno -l sačuvano je bez izuzetaka kod imenica (kotâl, posâl, vôl, fažôl, maštêl), kod pridjeva na -el i -al (dëbel, tëpal, mr̈zal) i kod muškog roda glagolskoga pridjeva radnoga (dëlal, morâl, rëkal, pâl).

Ovim mjesnim govorima karakteristični su i brojni konsonantski skupovi: /šć/(dvorĩšće, ognjĩšće, šćâp, ścuùpac, křšćen, jügrališće), osim ako je do nje došlo iz stare skupine /čt/ kada se javlja skupina /št/ (pöšten, pošt od posuđenica od skupine /st/ (štäla, štr̈aj, štümak, štãcija), odnosno ako je u posuđenicama provedena zamjena suglasnika u suglasničkim skupinama $/ s k / \mathrm{u} /$ šk/ (škãmlica, škâmlica, škapülat, škätula), /sp/u /šp/ (špïjat, šprëngovat, špârat),

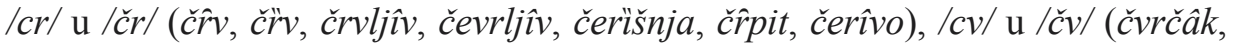
čvř̌cat, čvr̈knut, čvïka). Uobičajena je i pojava gubljenja $/ p /$ i /t/ u početnim

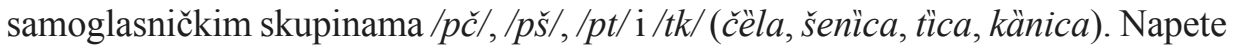
afrikate mijenjaju se frikativom (Otöšca, šenĩ̌ni, sinõšnji), zamjenjuju se skupovi

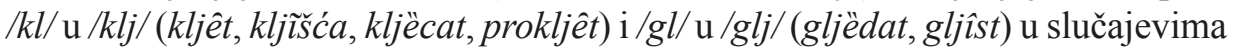
pojave ispred palatalnog vokala. Skupina $/ \mathrm{ml} /$ prelazi u $/ \mathrm{mlj} /$ (mljâk, mljëcav, mljâčit), odnosno skupina /gn/u /gnj/ (gnjüsan, gnjûs).

Za ove govore karakteristična je disimilacija kod skupova $/ \mathrm{mn} / \mathrm{i} / \mathrm{mnj} /$ (gũvno, dĩmljak, sümljat, tamljân), a također i disimilacija $/ r / \mathrm{i} / n / \mathrm{u} / l /$ (lëbro, slëbro, lümer, rôl). Također je poznat i rotacizam (mören, mörebit, mörda).

Konsonantska skupina /jd/ u prezentskoj osnovi kao konzervativna značajka prisutna je u prezentu glagola na -ći: laj/ (nãjdeš, snãjdeš se), lej/ (prẽjdeš), /oj/ (põjdeš).

\footnotetext{
${ }^{4}$ M. MOGUŠ, 1992.
} 
U deklinacijama imenica dobro su očuvani stari množinski oblici, osobito kod imenica muškog roda (kljûči, nôži, völi, br̂́ci, sïri). Genitiv množine imenica ženskog roda zadržava stari nastavački morfem -ø (ovâc, nôg, vrî́). Morfem -ø je i kod genitiva množine imenica s nepostojanim a (müsec dân, püno mân, mälo präsac, desẽtak janjâc). Genitiv množine imenica muškoga roda dobiva nastavak -ov ili -ev (đakôv, šëncov, küpcov, medvïdov, präščićev). Genitiv množine imenica srednjega roda pojavljuje se s nastavkom -ø i -ev (dëvet sêl, od brvan, nẽma drv, püno âvtov). U dativu množine u brinjskim govorima kod imenica muškog i srednjeg roda sačuvan je stari nastavak -om (težakuôm, voluôm, tielciêm), kod imenica ženskog roda na -a nastavak -am (dâj ovcâm, ženâm je tëže, güskam), dok u otočkim govorima ima nastavak -ami (dâj ovcämi, bãci kr̈avami). U lokativu množine kod imenica sačuvan je stari oblik bez krajnjeg $-h$ (po tuniêli, na völi, po brĩzi, u prsî, na köli, po lẽđi). U instrumentalu množine se kod imenica muškoga i srednjega roda zadržava konzervativni morfem -i ( $z$ drvî, zũbi je otkïnul). U instrumentalu množine imenica ženskoga roda na - $a$ javlja se nastavak -ami (s rukämi, š cìżmami, s pläktami), ali se javlja i lokativni oblik u instrumentalnom značenju ( $s$ kräva, s rukâ, s kokošâ), kao i instrumentalni oblik u lokativnom značenju (na cëstami). Dativ množine zamjenica mî, vî, öni javlja se u obliku: $m \hat{\imath}-n a ̈ n, v \hat{\imath}-v a ̈ n, o ̈ n i-\ddot{i} n$.

Pokazne zamjenice $o v a j$, onaj, najčešće gube početno -o ( $v \hat{a} j, v \hat{a}, v \hat{o}$; nâj, $n \hat{a}, n o ̂)$. Pokazna zamjenica taj može dobiti početno -o (öto, otôj, otômu, otôn).

Treće lice prezenta uvijek završava nastavcima -adu (poljĩvadu, pĩtadu, dëladu), -edu (grẽdu, pečẽdu, smïćedu se) i -idu (mïslidu, dĩčidu se, stoĩdu).

Poznate su u svim gackim čakavskim govorima i protetske pojave (Jive, jöpet, jâpno, jüžina).

U gackima čakavskim govorima poznati su neki kontrahirani oblici u futuru 3. 1. množine ( $p a ̈ j d u$ - pa će, nẽjdu - ne će, köjdu konẽjdu - ako će, ako neće, säjdu - sad će, käjdu - kad će, mäjdu - ma će, däjdu - da će).

\section{Briga o gackoj čakavštini}

Katedra Čakavskog sabora pokrajine Gacke, osnovana 1997. godine u Otočcu, vodila je višegodišnju borbu kako bi se uklonio inferiorni osjećaj autohtonih čakavskih govornika jer su bili izloženi poruzi štokavskih govornika te kako bi se spoznala vrijednost svakoga narječja u odnosu na standardni hrvatski književni jezik.

U osnovnim školama, ponešto i u Srednjoj školi Otočac, u zoni zavičajne nastave potiče se govor i pisanje na čakavštini. Nositelj javne riječi na gackoj 
čakavštini je Hrvatski radio Otočac, ali i drugi elektronički mediji vjerni su prenositelji čakavštine (portal GlasGacke.hr). ${ }^{5}$

Katedra je pokrenula i tiskanje knjiga različita sadržaja zavičajnosti (dosad je tiskano više od 30 naslova). ${ }^{6}$ Poticala je također literarno stvaralaštvo te stručno i znanstveno istraživanje ovih govora. Pomogla je Gackom pučkom otvorenom učilištu u brojnim folklornim i drugim večerima pišući na gackoj čakavštini skečeve ili kraće dramske tekstove, a to se poprilično odnosilo i na Smotru folklora u Otočcu koja je prerasla u tradicionalnu smotru.

Gacka čakavština je zbog promjene stila života veoma ugrožena. Posebno se to odnosi na seoski način života, odnosno na nazivlje u alatima i tradicijskoj opremi kućanstva. No, gacka čakavština je prilično živa, u svoj leksik lako prihvaća pojmove iz standardnoga hrvatskoga jezika ili čak stranih jezika, prilagođavajući ih svojemu jezičnom sustavu (härdverov, krododïlov, möbitelov, chätadu, mëjlat). ${ }^{7}$

\section{Ugroženost gacke čakavštine}

Gacka čakavština okružena je djelomično štokavskim dijalektima, dok je na sjeveru naslonjena na čakavske mjesne govore Modruša, Ogulina te sve do Duge Rese i Ozlja. Od Senja i primorske čakavštine odijeljena je uskim štokavskim pojasom. Međutim, unatoč izloženosti utjecaju štokavskih dijalekata, čakavskim govorima svojstven je jaki konzervativizam te u vokabularu, a pogotovo u prozodiji, nije bilo značajnijih utjecaja. Međutim, s druge strane, u sustavu obrazovanja ne postoje dovoljno jaki mehanizmi koji bi ukazivali na jednakovrijednost svih dijalekata hrvatskoga jezika, odnosno poticali mlade u korištenju i očuvanju mjesnih govora. Sveopća izloženost medijima također, nažalost, ne pridonosi tom cilju kao ni činjenica da u školama gacki čakavski govori nisu proskribirani, već se u nastavnom procesu koliko-toliko potiče uporaba, barem u izvannastavnim aktivnostima. U svakom slučaju, ojačana dijalektalna osviještenost postepeno umanjuje kompleks manje vrijednosti čakavskih govornika.

Zaštita gackih čakavskih govora nadasve je poželjna kako bi se održali ovi govori. Ukupno je nekih 13.000 govornika te su prema tome gacki govori na granici ugroženosti dijalekta. Opstankom ovih govora čuva se lokalni identitet i hrvatsko jezično bogatstvo raznolikosti.

\footnotetext{
${ }^{5}$ M. KRANJČEVIĆ, 2018, 18-22.

${ }^{6}$ M. KRANJČEVIĆ, 2018, 91-140.

${ }^{7}$ M. KRANJČEVIĆ, 2009, 403-405.
} 


\section{Zaštita gackih čakavskih govora s područja Otočca}

Katedra Čakavskog sabora pokrajine Gacke se tek nakon višedesetljetnog rada i djelovanja osmjelila predložiti Ministarstvu kulture zaštitu gackih govora, predmnijevajući da je prethodno potrebno mnogo toga učiniti u očuvanju i promoviranju te čakavštine. Vlastitim snagama i znanjem predala je ispunjen obrazac Ministarstvu kulture u ožujku 2017. Prijedlog je morao proći određene faze ocjenjivanja i valoriziranja. Povjerenstvo za nematerijalnu kulturnu baštinu ocijenilo je na sjednici 29. svibnja 2017. da gacki čakavski govori zaslužuju dobiti zaštitu te je prijedlog krenuo u daljnju proceduru. Stručno povjerenstvo za utvrđivanje svojstva kulturnog dobra je na sjednici 29. svibnja 2018. utvrdilo da gacki čakavski govori imaju svojstvo nematerijalnoga kulturnog dobra, dok je Uprava za zaštitu kulturne baštine Ministarstva kulture 8. lipnja 2018. konačno donijela i rješenje o utvrđivanju državne zaštite predloženim govorima.

Katedra je doduše, po preporuci stručnjaka s Instituta za hrvatski jezik i jezikoslovlje, u sustav zaštite ugradila i brinjske čakavske mjesne govore, ali tijekom postupka su do Ministarstva došli signali da će Brinjaci sami provesti postupak zaštite, stoga je prijedlog reduciran na zaštitu otočkih govora.

Gacki čakavski govori uvršteni su na Listu zaštićenih kulturnih dobara Republike Hrvatske na kojoj se zasada nalaze 22 dijalekta. Gacki čakavski govori s područja Otočca nalaze se u društvu Bednjanskoga govora, Cokavskih govora otoka Visa, Čabarskih govora, Dubrovačkoga govora, Govora Dubravice, Govora Huma na Sutli, Govora i toponimije sela Vidonje, Govora otoka Suska, Govora posavskoga sela Siče, Govora Starih Perkovaca, Govora zadarskih Arbanasa, Govora milnarskog područja, Grobničke čakavštine, Istro-rumunjskih govora, Kajkavskog donjosutlanskog (ikavskog) dijalekta, Kotoripske skupine govora, Splitskoga govora (splitska čakavština), Šoltanskih čakavskih govora, Štrigovske skupine govora, Turopoljskog dijalekta i Žminjskoga govora. Dakle, gacki čakavski govori s područja Otočca su 21. po redu zaštićeni (pod)dijalekt hrvatskoga jezika.

Zaštita jednoga kulturnog dobra nije sama sebi svrha. Važno je što država prepoznaje kulturno dobro $i$ što ga smatra vrijednim na nacionalnoj razini. $U$ isto se vrijeme time stvara i obveza očuvati to kulturno dobro, a kada su u pitanju gacki čakavski govori s područja Otočca, to znači širenje obveze na sve one koji tomu mogu pridonijeti: od škola, knjižnica, pučkih učilišta, lokalne samouprave pa do raznih udruga koje se bave kulturnim fenomenima.

Najvažnije je poticati mlade na korištenje govorne i pisane riječi, širiti pozitivno okružje kod autohtonih govornika, a potom poraditi na gramatici te rješavanju nekih pravopisnih dilema u gackim čakavskim govorima. 


\section{Literatura}

Božidar FINKA - Milan MOGUŠ, Karta čakavskog narječja, Hrvatski dijalektološki zbornik, 5, Zagreb, 1981, $49-58$.

Milan KRANJČEVIĆ, Položaj gacke čakavštine u odnosu na čakavsko narječje, Identitet Like, Gospić, 2009, 401-417.

Milan KRANJČEVIĆ, Katedra Čakavskog sabora pokrajine Gacke 1997. - 2017., Otočac, 2018.

Iva LUKEŽIĆ, Čakavski ikavsko-ekavski dijalekt, Rijeka, 1990.

Milan MOGUŠ, O naglasnom sustavu čakavštine u Gackoj dolini, Suvremena lingvistika, 33, Zagreb, 1992, 235-242.

\section{PRILOG: Osnovna literatura o gackoj čakavštini}

\section{Knjige $i$ članci}

Dalibor BROZOVIĆ, Dijalekatska slika hrvatskosrpskoga jezičnog prostora, Radovi Filozofskog fakulteta u Zadru, 8, Zadar, 1970.

Dalibor BROZOVIĆ, Čakavsko narječje, u separatu "Jezik srpsko-hrvatski/hrvatskosrpski ili srpski", Zagreb, 1998.

Jasminka BRALA-MUDROVČIĆ, Čakavska terminologija Otočca i okolice, Grad Otočac, 8, Otočac, 2005.

Jasminka BRALA-MUDROVČIĆ, Toponimi Gacke doline, Folia onomastica croatica, 23, Zagreb, 2015.

Jasminka BRALA-MUDROVČIĆ, Čakavska imena naseljenih mjesta u južnoj Gackoj, Vrilo, 13, Otočac, 2016.

Mirjana DASOVIĆ, Germanizmi u Gackoj dolini vezani za seljački život, Filozofski fakultet u Zagrebu (seminarski rad na Poslijediplomskom studiju), Zagreb, 2000.

Mirjana DASOVIĆ-Milan KRANJČEVIĆ, Germanizmi u čakavskim mjesnim govorima južne Gacke, Grad Otočac, 7, Otočac, 2000.

Božidar FINKA-Slavko PAVEŠIĆ, Rad na proučavanju čakavskog govora u Brinju i okolici, knjiga 1, Zagreb, 1968.

Božidar FINKA, O čakavskom identitetu, Suvremena lingvistika, 7-8, Zagreb, 1973.

Jure GRČEVIĆ, Kompolje - narodni život i običaji, Kompolje, 2000.

Stipe KEKEZ, Vrijedan prinos proučavanju gacke čakavštine, Rasprave Instituta za hrvatski jezik i jezikoslovlje, 30(1), Zagreb, 2004.

Manja KOVAČEVIĆ, M. Kranjčević - "Ričnik gacke čakavšćine", Lička revija, 5, Gospić, 2005.

Milan KRANJČEVIĆ, Ričnik Gacke čakavšćine - Konpoljski divan, Otočac, 2003.

Milan KRANJČEVIĆ, Deklinacije u čakavštini južne Gacke, Grad Otočac, 8, Otočac, 2005.

Stjepan KRPAN, Brinjski kraj u prošlosti i sadašnjosti - prilozi za monografiju, Zagreb, 1995. Josip LISAC, Hrvatska dijalektologija 2. Čakavsko narječje, Zagreb, 2009.

Iva LUKEŽIĆ, Zajednička povijest hrvatskih narječja, Zagreb, 2012.

Nikola MARINIĆ - Ivan ROŽMAN, Kuterevo u prošlosti i sadašnjosti 1670. - 2007., Kuterevo, 2007. 
Milan MOGUŠ, Izvještaj o ispitivanju čakavaca u Lici, Zagreb, 1960.

Milan MOGUŠ, Čakavsko narječje, Zagreb, 1977.

Jelena ODORČIĆ, Derivacijska tvorba imenica u mjesnom govoru Kompolja, Filozofski fakultet Rijeka (diplomski rad), Rijeka, 2015.

Sanja OREŠKOVIĆ, Prvi opis mjesnog govora Kompolja, Pedagoški fakultet Rijeka (diplomski rad), Rijeka, 1998.

Snježana OREŠKOVIĆ, Gacka čakavština, Grad Otočac, 2, Otočac, 1996.

Snježana OREŠKOVIĆ, Mjesni govor Kutereva, Pedagoški fakultet Rijeka (diplomski rad), Rijeka, 1986.

Valentina RUPČIĆ, Mjesni govor Čovića, Filozofski fakultet Rijeka (završni rad), Rijeka, 2015.

Lucija SEKULA, Osnovne karakteristike mjesnog govora Prozora, Grad Otočac, 7, Otočac, 2003.

Nikola TOMINAC, Stajnica i okolica (monografija), Zagreb, 2004.

\section{Audiovizualni izvori}

Hrvatski radio Otočac - arhiv

\section{Internetski izvori}

Glas Gacke, URL: GlasGacke.hr

\section{GACKA CHAKAVIAN DIALECT FROM THE REGION OF OTOČAC}

- a protected intangible cultural asset of the Republic of Croatia

\section{Summary}

The Gacka Chakavian dialects in the region of Gacka are ancient dialects, they belong to the Chakavian dialect, by classification they are part of the Ikavian-Ekavian dialect and are then split into two groups of sub-dialects, marginal and continental (Kuterevo), in order that everything is returned to its source, to the local dialect of individual settlements.

Gacka Chakavian is, viewed historical, a remnant of the former prevailing Chakavian dialect not only in the area of today's Gacka, Lika and Krbava, but also of much further afield. However, due to the Ottoman incursions in the Middle Ages, this linguistic region was on the Vrbas Neretva line pushed towards the west, the settling occurred of a new population who belonged to the Shtokavian dialect. In modern times Gacka Chakavian is preserved in two areas, in the region of Otočac and the region of Brinje. It relies on the Senj, in other words, Modruš-Ogulin Chakavian and beyond, all the way to the southern ends of Karlovac, in other words, Ozalj.

Gacka Chakavian was, like all other X-kavian dialects, as well as many Shtokavian, repressed in the field of public communications. It needed a great deal of effort so that native speakers dared and were encouraged to use it more, and the Chair of the Chakavian Assembly of the Gacka Region was also established with the aim of the promotion and protection of this Chakavian dialect. All of this, after 20 years of the work of the Chair, resulted in the protection of Gacka Chakavian with the region of Otočac as the intangible cultural heritage of the Republic of Croatia.

Keywords: Gacka Chakavian, intangible cultural heritage, Otočac 